\title{
Equestrian-Related Traumatic Brain Injury in the Pediatric Population
}

\author{
Ha Son Nguyen Sean Lew \\ Department of Neurosurgery, Medical College of Wisconsin and Children's Hospital of Wisconsin, \\ Milwaukee, Wis., USA
}

\section{Key Words}

Equestrian-related injuries $\cdot$ Horse $\cdot$ Head injury $\cdot$ Traumatic brain injury

\begin{abstract}
Background: Equestrian activities can be undertaken for competition or leisure. Accidents can lead to bodily injuries. In particular, traumatic brain injury (TBI) can be devastating. Limited data exist regarding the pediatric population with respect to patterns of injury and related neurosurgical intervention. Methods: We retrospectively reviewed data for all pediatric patients diagnosed with equestrian-related injuries with neurological injuries from 2005 through June 2015. Results: Nine patients ( 1 male and 8 females) had neurological injuries. Their mean age was 10.4 years (range $2.9-16.8$ years). Intracranial pathologies ranged from small punctate hemorrhages to large surgical extra-axial hematomas. Five patients also had concurrent skull fractures; 2 exhibited open lesions. Two patients required a decompressive craniotomy with placement of an external ventricular drain. Three patients exhibited other minor injuries; none had thoracic/ abdominal/pelvic injuries. At discharge, all had good recovery; 1 patient who had a craniotomy did have a persistent right third-nerve palsy. Conclusion: Equestrian activities can present with dangerous and unpredictable situations, which
\end{abstract}

\begin{tabular}{ll}
\hline KARGER & ( 2016 The Author(s) \\
& Published by S. Karger AG, Basel \\
& $1016-2291 / 16 / 0516-0279 \$ 39.50 / 0$
\end{tabular}

can lead to profound neurological injury. Caution should be observed for all involved members, as both riders and nonriders are susceptible to harm. Protective gear (such as helmets), adequate training, and extensive experience are encouraged.

(C) 2016 The Author(s)

Published by S. Karger AG, Basel

\section{Introduction}

Equestrian activities can be undertaken for competition (racing, jumping, polo, and rodeo) or leisure. Associated accidents can lead to bodily injuries. In particular, traumatic brain injury (TBI) can be devastating. Limited data exist regarding the pediatric population with respect to patterns of injury and related neurosurgical intervention $[1,2]$. We sought to evaluate the patterns of brain injury associated with equestrian activities in a single-institution 10-year review.

\section{Methods}

The institutional review board at our hospital approved this study.

We retrospectively collected data for all pediatric patients diagnosed with equestrian-related injuries from 2005 through June 
Table 1. Patient summaries

\begin{tabular}{|c|c|c|c|c|c|c|c|c|c|c|}
\hline $\begin{array}{l}\text { Pa- } \\
\text { tient }\end{array}$ & $\begin{array}{l}\text { Age, } \\
\text { years }\end{array}$ & $\begin{array}{l}\text { Gen- } \\
\text { der }\end{array}$ & Mechanism & Skull Fx & $\begin{array}{l}\text { Hel- } \\
\text { met? }\end{array}$ & Intracranial findings & $\begin{array}{l}\text { Initial } \\
\text { GCS }\end{array}$ & Surgery & Other injuries & $\begin{array}{l}\text { Discharge } \\
\text { exam }\end{array}$ \\
\hline 1 & 7.3 & $\mathrm{~F}$ & fell off horse & $\begin{array}{l}\text { closed right parietal } \\
\text { nondisplaced skull } \\
\text { Fx }\end{array}$ & no & $\begin{array}{l}\text { right parietal } 8-\mathrm{mm} \\
\text { epidural hematoma, } \\
\text { contusion }\end{array}$ & 14 & no & none & nonfocal \\
\hline 2 & 16.8 & $\mathrm{~F}$ & fell off horse & none & yes & $\begin{array}{l}\text { left lateral ventricle } \\
\text { hemorrhage }\end{array}$ & $10 \mathrm{~T}$ & no & none & nonfocal \\
\hline 4 & 9.7 & $\mathrm{~F}$ & $\begin{array}{l}\text { kicked by } \\
\text { horse }\end{array}$ & $\begin{array}{l}\text { opened left } \\
\text { temporoparietal } \\
\text { skull Fx }\end{array}$ & n.a. & contusion & $6 \mathrm{~T}$ & $\begin{array}{l}\text { left decompressive } \\
\text { craniectomy with } \\
\text { expansion dura- } \\
\text { plasty and left EVD }\end{array}$ & right thigh abrasion & nonfocal \\
\hline 6 & 2.9 & M & $\begin{array}{l}\text { kicked by } \\
\text { horse }\end{array}$ & $\begin{array}{l}\text { closed right frontal } \\
\text { skull Fx }\end{array}$ & n.a. & $\begin{array}{l}\text { subtle extra-axial } \\
\text { hemorrhage }\end{array}$ & 15 & no & none & nonfocal \\
\hline 7 & 9.5 & $\mathrm{~F}$ & $\begin{array}{l}\text { kicked by } \\
\text { horse }\end{array}$ & $\begin{array}{l}\text { opened right orbital } \\
\text { Fx, closed right frontal }\end{array}$ & n.a. & $\begin{array}{l}\text { right frontal } \\
\text { epidural hematoma }\end{array}$ & 15 & no & nail bed laceration & nonfocal \\
\hline 8 & 13.1 & F & $\begin{array}{l}\text { fell off horse } \\
\text { and horse } \\
\text { rolled over her }\end{array}$ & none & n.a. & $\begin{array}{l}\text { mild deep shear } \\
\text { injury }\end{array}$ & 10 & no & none & nonfocal \\
\hline 9 & 13.8 & F & $\begin{array}{l}\text { thrown from } \\
\text { a horse }\end{array}$ & none & n.a. & $\begin{array}{l}\text { left parietal punctate } \\
\text { hemorrhage }\end{array}$ & 15 & no & none & nonfocal \\
\hline
\end{tabular}

2015. Patients with signs of TBI found in CT scans were included in the study. Subsequently, data were collected, which included age, gender, mechanism of injury, presence and extent of neurological injury, neurological examination, treatment modality, other injuries, and outcome at discharge.

\section{Results}

Table 1 summarizes the patient population. There were a total of 20 patients with equestrian-related injuries. Nine patients ( 1 male and 8 females) had neurological injuries and were included in the study. Their mean age at presentation was 10.4 years (range 2.9-16.8 years). Helmet status was only available for 2 patients. Intracranial pathologies ranged from small punctate hemorrhages to large surgical extra-axial hematomas. Five patients also had concurrent skull fractures; 2 exhibited open le- sions. Patients 3 and 4 both required a decompressive craniotomy with placement of an external ventricular drain (EVD); their cases are discussed below. Three patients exhibited other minor injuries; none had thoracic/abdominal/pelvic injuries. At discharge, all had good recovery; patient 3 did have a persistent right ptosis and right nonreactive pupil.

\section{Patient 3}

A 13-year-old female sustained a kick by a horse. Upon emergency medical service arrival, she was unresponsive and exhibited decorticate posturing. She was intubated in the field. Imaging demonstrated left $>$ right subdural hematoma, along with multiple facial fractures (bilateral Le Fort 3)/skull fractures (through sphenoid sinus and sella, right frontal, bilateral temporal, left parietal, and right orbital) (fig. 1). She underwent an emergent left craniotomy for hematoma evacuation and 


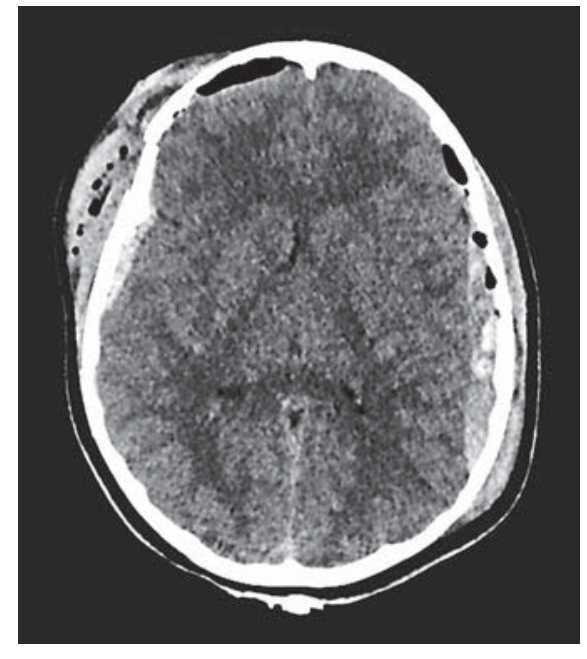

Fig. 1. Patient 3.

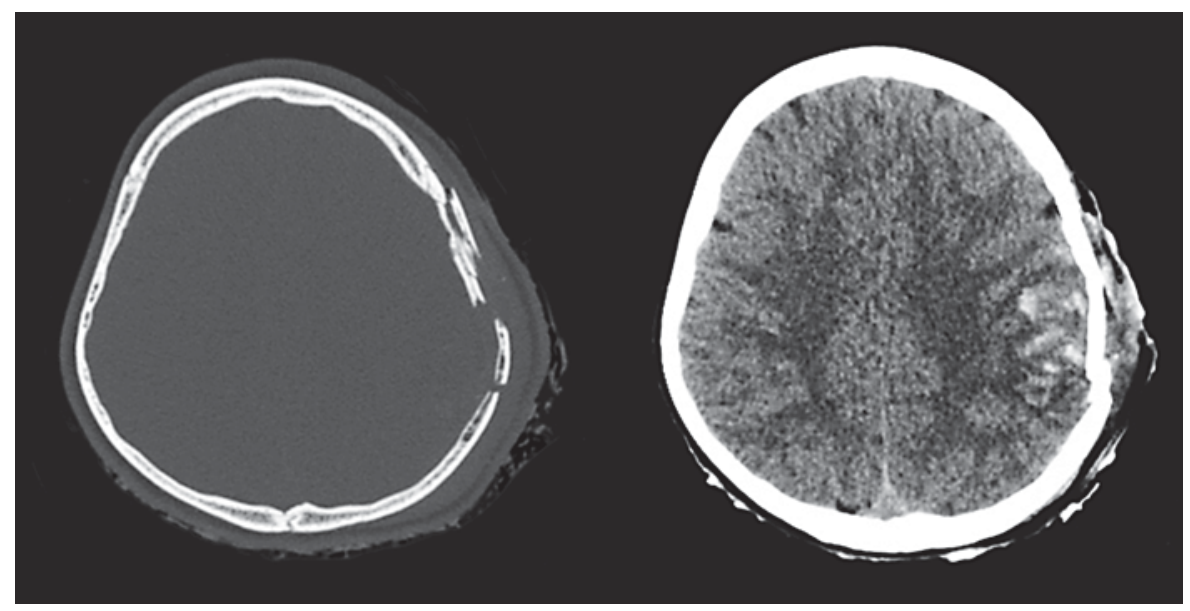

Fig. 2. Patient 4. placement of an EVD. Postoperatively, she withdrew briskly in all four extremities. She was kept intubated and sedated. She exhibited diabetes insipidus and was managed with DDAVP. Initially, she exhibited an active CSF leak from her nose. ENT packed her nose, and the EVD was employed generously to stifle her leak. She was kept on broad-spectrum antibiotics. CSF leak was controlled until postoperative day (POD) 7, when her EVD became nonfunctional, and drainage was noted from the left nares. A lumbar drain was placed afterwards. On POD 9, sedation was weaned, and she began to follow commands by waving her right hand and wiggling bilateral toes; her left extremity remained purposeful. Starting POD 10, the drain was slowly weaned; by POD 13, the drain was removed. At discharge, approximately 1 month after the injury, she exhibited persistent third-nerve palsy, but no CSF leak. Neurocognitive testing revealed no significant findings.

\section{Patient 4}

A 9-year-old female presented after a horse had kicked her in the head. She was reportedly Glasgow Coma Scale (GCS) 10 in the field. On arrival, she exhibited GCS 7, and was intubated and sedated. On examination, she did not open her eyes to pain, her pupils were $2 \mathrm{~mm}$ and sluggishly reactive, and she exhibited withdrawal in all extremities. There was visible bone over the left convexity with associated scalp hematoma. A CT of the head revealed a left temporoparietal skull fracture with underlying contusion (fig. 2). Subsequently, she underwent a left decompressive craniectomy and place- ment of an EVD. OR cultures were sent. Shortly, she began to follow commands and was extubated on POD 6. EVD was weaned without ICP issues, and was removed on POD 8. At discharge, approximately 1 month after presentation, she exhibited a nonfocal neurological examination. She returned 7 weeks after injury for a cranioplasty with a custom PEEK implant. Three weeks later, she exhibited headache, irritability, increased left facial swelling, and low-grade fever. An MRI revealed an intracranial subdural fluid collection with enhancement along the left frontoparietal temporal cranioplasty site. She was taken to the OR that evening for wound exploration with removal of the PEEK implant, and washout of subgaleal and epidural purulence. There was no evidence of a subdural infection. OR cultures grew MSSA, for which 3 weeks of intravenous ceftriaxone was recommended. Two weeks after finishing her antibiotics, she underwent left cranioplasty with a custom implant. She presented 6 weeks later with a superficial wound dehiscence associated with a stitch abscess, which was explored and revised. She was placed on a 1-week course of oral Keflex. Functionally, she exhibited behavioral challenges (memory issues, frequent distractions, and persistent fatigue). She was initially started on Prozac, but was later transitioned to Vyvanse and Ritalin. Formal neuropsychological testing showed good cognitive recovery but persistent issues with emotion and behavior. Moreover, she continued to have headache and was referred to a pain clinic. 


\section{Discussion}

From 2001 to 2009, the annual number of visits to the emergency department (ED) for TBI related to sports and recreation activities among people $\leq 19$ years steadily rose yearly, in excess of 248,000 by 2009 [3]. Less than $1 \%$ of the ED visits were related to horseback-riding [3]. However, for patients who sustained injuries due to horseback riding, 15.3\% also exhibited TBI [3]. Surprisingly, injury severity scores associated with accidents involving equestrian activities are higher than those involving bicycles, motorcycles, ATVs, and motor vehicles [4-7]. In addition, equestrian activities demonstrate higher mortality rates than football, rugby, motor racing, and skiing [4]. Overall, equestrian-related TBI can pose significant socioeconomic ramifications related to hospital costs and neurocognitive disabilities [1,8-10].

The majority of pediatric patients brought to the ED for equestrian-related injuries have been females $[1,6$, 11-13]. This observation may be related to the higher participation rates by females in equestrian sports/activities $[6,7]$. Many critical injuries are sustained when riders fall from horses, where they can also be subsequently crushed or hauled against the ground [7]. Injuries may also occur during nonriding activities. Kicks to dismounted people represent about $2-40 \%$ of equestrian-related injuries; this may occur during grooming, feeding, handling, shoeing, or saddling the horse; other mechanisms include biting, pulling, standing/rolling on the rider, and striking the rider with abrupt head movements [2, $6,7,11,13]$. Injuries are more common in less experienced riders $[1,14]$. Prior recommendations have encouraged helmet use $[4,7,12]$ and higher levels of training/experience/supervision $[1,14]$.

The most frequent equestrian-related injuries among those $\leq 18$ years old who arrive to the ED are head/skull/ facial injuries, superficial trauma to the skin and subcutaneous tissues, fractures along the extremities, and internal injuries (abdomen/thorax/pelvis) [7, 13, 15]. Compared to adults, children may be at higher risk for TBI given the greater head-to-body size ratio, thinner skull bones, and lesser myelinated neural tissue [16]. Equestrian-related TBI varies from mild concussions to severe, structural damages with associated neurological deficits or death. Limited literature exists which details neurological injuries and operative procedures in the pediatric population. Cuenca et al. [1] found that $23 \%$ of 87 admitted pediatric patients exhibited head injuries, where 2 suffered cerebral contusions and required craniotomies. Kriss and Kriss [2] noted that within their cohort of 30 patients with neurological injuries, there were 24 cranial injuries and 9 spinal injuries ( 3 patients sustained both). Five patients needed a ventriculostomy, 6 endured a craniotomy, and 3 had spinal procedures [2]. Five patients died while 2 exhibited long-term paralysis; 15 patients were neurologically intact at the long-term follow-up. Ghosh et al. [13] commented that within their group of 315 pediatric patients with horse-related injuries, there were 57 intracranial hemorrhages, 27 cerebral contusions or lacerations, and 16 intracranial injuries where 48 neurosurgical procedures were performed. Outcomes were generalized, where 8 patients were discharged to a rehabilitation facility for CNS injury. Kiss et al. [6] documented that within their study of 265 pediatric patients, 23 sustained head injuries (13 with severe brain contusion, skull fracture, and intracranial hemorrhage, and 10 with mild injuries). Reports regarding open skull fractures in TBI have also been sparsely mentioned through case series, where only a few were casually mentioned $[12,13]$.

Our cohort of patients also exhibited a female prevalence. Unfortunately, helmet status was unknown for 7 of the 9 patients. Despite the small sample size, the extent of neurological injury was variable, ranging from mild signs of shear injury to large surgical pathologies. All 9 patients had good recovery. One of the two surgical patients had extensive issues associated with cranioplasty infection; plausibly, the initial contaminated open wound was a risk factor.

\section{Conclusion}

Equestrian activities can present with dangerous and unpredictable situations, which can lead to profound neurological injury. Caution should be observed for all involved members, as both riders and nonriders are susceptible to harm. Protective gear (such as helmets), adequate training, and extensive experience are encouraged.

\section{Disclosure Statement}

There is no conflict of interest. 


\section{References}

$>1$ Cuenca AG, Wiggins A, Chen MK, Kays DW, Islam S, Beierle EA: Equestrian injuries in children. J Pediatr Surg 2009;44:148-150.

$\checkmark 2$ Kriss TC, Kriss VM: Equine-related neurosurgical trauma: a prospective series of $30 \mathrm{pa}$ tients. J Trauma 1997;43:97-99.

-3 Casey D, Chaudhary BR, Leach PA, Herwadkar A, Karabatsou K: Traumatic clival subdural hematoma in an adult. J Neurosurg 2009; 110:1238-1241.

4 Zuckerman SL, Morgan CD, Burks S, Forbes JA, Chambless LB, Solomon GS, Sills AK: Functional and structural traumatic brain injury in equestrian sports: a review of the literature. World Neurosurg 2015;83:10981113.

5 Bleetman D: The equestrian sport-related injury workload of a regional doctor-led air ambulance unit. Injury 2012;43:2023-2025.

6 Kiss K, Swatek P, Lenart I, Mayr J, Schmidt B, Pinter A, Hollwarth ME: Analysis of horserelated injuries in children. Pediatr Surg Int 2008;24:1165-1169.
7 Jagodzinski T, DeMuri GP: Horse-related injuries in children: a review. WMJ 2005;104: 50-54.

-8 Guyton K, Houchen-Wise E, Peck E, Mayberry J: Equestrian injury is costly, disabling, and frequently preventable: the imperative for improved safety awareness. Am Surg 2013;79: 76-83.

$\checkmark 9$ Ryan NP, van Bijnen L, Catroppa C, Beauchamp MH, Crossley L, Hearps S, Anderson $\mathrm{V}$ : Longitudinal outcome and recovery of social problems after pediatric traumatic brain injury (TBI): contribution of brain insult and family environment. Int J Dev Neurosci 2016; 49:23-30.

$\checkmark 10$ Zonfrillo MR, Zaniletti I, Hall M, Fieldston ES, Colvin JD, Bettenhausen JL, Macy ML, Alpern ER, Cutler GJ, Raphael JL, Morse RB, Sills MR, Shah SS: Socioeconomic status and hospitalization costs for children with brain and spinal cord injury. J Pediatr 2016;169: 250-255.
1 Eckert V, Lockemann U, Puschel K, Meenen NM, Hessler C: Equestrian injuries caused by horse kicks: first results of a prospective multicenter study. Clin J Sport Med 2011;21:353355

12 Loder RT: The demographics of equestrianrelated injuries in the United States: injury patterns, orthopedic specific injuries, and avenues for injury prevention. J Trauma 2008; 65:447-460.

13 Ghosh A, Di Scala C, Drew C, Lessin M, Feins $\mathrm{N}$ : Horse-related injuries in pediatric patients. J Pediatr Surg 2000;35:1766-1770.

14 Mayberry JC, Pearson TE, Wiger KJ, Diggs BS, Mullins RJ: Equestrian injury prevention efforts need more attention to novice riders. J Trauma 2007;62:735-739.

15 Bilaniuk JW, Adams JM, DiFazio LT, Siegel BK, Allegra JR, Lujan JJ, Durling-Grover R, Pawar J, Rolandelli RH, Nemeth ZH: Equestrian trauma: injury patterns vary among age groups. Am Surg 2014;80:396-402.

16 Kannan N, Ramaiah R, Vavilala MS: Pediatric neurotrauma. Int J Crit Illn Inj Sci 2014;4: 131-137. 